\title{
RESEARCH OF TECHNOLOGICAL PROCESS FOR MEDICINAL PLANT SEPARATION
}

\author{
Augustina Pruteanu ${ }^{1}$, Mihai Matache ${ }^{1}$, Adriana Muscalu ${ }^{1}$, Ladislau David ${ }^{2}$ \\ ${ }^{1}$ National Institute of Research - Development for Machines and Installations Designed to Agriculture \\ and Food Industry, Bucharest, Romania; ${ }^{2}$ University Politehnica of Bucharest, Romania \\ pruteanu_augustina@yahoo.com, gabimatache@yahoo.com, amuscalis@yahoo.com, \\ david.ladislau@yahoo.com
}

\begin{abstract}
Medicinal plants contain biologically active substances with therapeutic value. Primary and advanced processing of medicinal plants is important for assuring an enhanced quantity of raw materials and preserving or increasing their valuable constituents. Obtaining available high quality phyto-therapeutic products is possible only by using state-of-the art technical equipment adapted to each plant requirements. The technological separation process of medicinal plants on sieves is a complex process and is influenced by many factors: sieve charge, sieve dimension, components of vegetal material, dimension difference between plant fragments and the holes they pass through, sieve cinematic regime, plant humidity and their content of bioactive substances, etc. Based on correlations between the presented elements one can establish the technological parameters of the sorting process so that to make a quality separation. This paper presents experimental data on the separation process of nettle herb (Urtica dioica) and chicory herb (Cichorium intybus) on the length of flat vibrating sieves depending on the flow rate and sieve angle of inclination. In order to find an optimal separating efficiency and to characterize the separation process of nettle herb and chicory on the length of flat vibrating sieves we focus on: the separation intensity on the sieve length, cumulative separation on the sieve length and the efficiency of the separation process. The results are important for: medicinal plant processing, separating nettle and chicory herbs, designers of machines for separating medicinal plants and obtaining high quality phyto-therapeutic products.
\end{abstract}

Keywords: medicinal plants, separation process, length of flat vibrating sieves, separation efficiency.

\section{Introduction}

Vegetable raw material conditioning supposes all the measures taken for valorising their potential characteristics. Firstly, this is about foreign bodies removal and conferring the optimal sizes for processing, then preventing or limiting some chemical or biochemical processes during storage, resulting in worsening the quality and even alteration of raw materials [1]. The primary processing supposes all the operations of conditioning, harvesting, drying, grinding by chopping (cutting), transport, sorting, performed by specialized equipment and through which the raw material is successively transformed, quantitative and qualitative, from the initial state $S_{0}$ to a state of finished product $S_{K}$. From the structure point of view, the technological process of aromatic and medicinal plant primary processing represents the part of the processing process, which contains the total interlinked necessary operations and stages for preparing, respectively passing the harvested or purchased vegetable material in an appropriate condition for storage, packing or further processing within a production unit [2].

Medicinal plant separation aims at achieving size classes with higher and lower limits or welldefined particle size fractions. This separation is mechanically performed by sieving with the help of sieve mechanical separators [3]. Sieves can be classified in two groups: plane and cylindrical, plane sieves being widely used. The most important characteristics of a plane sieve are: mesh sizes, mesh shapes (round or square are dominant forms), sieve thickness and sieve shapes [4]. Essentially, the separation process consists in statistical comparison of the fragment dimension with the size (opening) of the sieve meshes. This requires that the material subjected to separation moves relative to the sieve surface, being dependent on the movement character that the sieve transmits to the material [5]. Actually, for fast and continuous separation of different materials, almost exclusively, vibrating/ oscillating separators are used, where the material movement is achieved by jumps on the sieve surface [6], because the particle downward trajectory is closed to vertical, facilitating the particles to pass through the sieve mesh [7].

The separating process consists of two regions: a "crowded" region (where fragments reach the sieve surface and the accumulation of fragments near the sieve mesh causes the fragments crowding and undersized fragments must pass through gaps between the oversize fragments) and a "separated" region (where fragments travel along the sieve, the apertures and the concentration of undersize 
fragments in the flowing near the sieve mesh). As the length of the sieve surface increases there are more opportunities for fragments to penetrate the apertures [8].

This paper presents the effect of the sieve length on the separation efficiency of medicinal plant fragments under various single parameter conditions including: the feed flow and sieve angle of inclination in order to find an optimal separating efficiency.

\section{Materials and methods}

The plant material used in the experiments, nettle (Urtica dioica) and chicory (Cichorium intybus), was harvested from the spontaneous flora of Romania and identified by morphological and biological characteristics of the species [9]. The herb was dried naturally in the shade, until it reached the storage humidity (maximum $13 \%$ ), cleaned of foreign bodies (inorganic materials or other plants, injured parties) under the provisions of [10,11], and then it was chopped in bulk using the TIMATIC grinder for medicinal plants, adjusted to the size of $6 \mathrm{~mm}$ for nettle and of $8 \mathrm{~mm}$ for chicory.

The experimental researches were conducted on a dimensional sorting equipment for chopped plants, existing in operation within INMA Bucharest, the design scheme is shown in Fig. 1 [12].

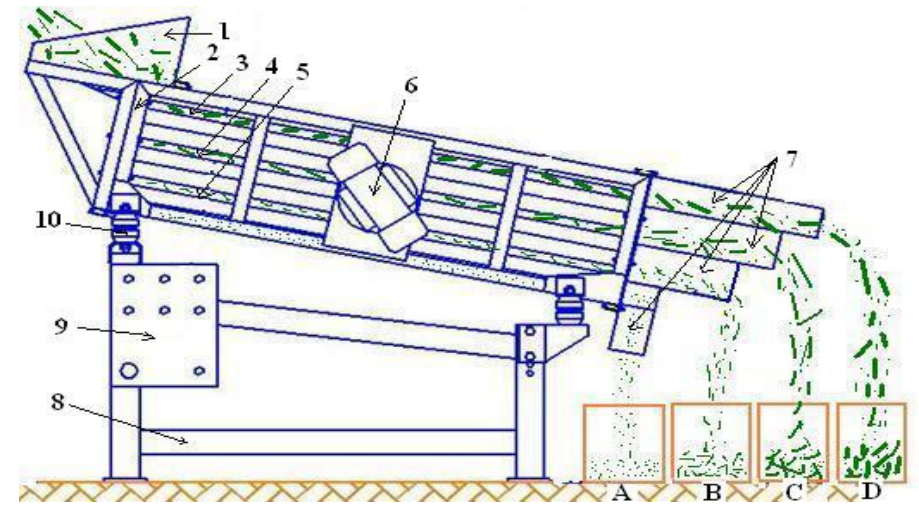

Fig. 1. Scheme of the equipment for sieving medicinal plants [12]: 1 - feeding hopper;

2 - bedframe; 3, 4, 5 - sieves with square holes of varying sizes (pos. 3 sieve with large holes, pos. 4 sieve with medium holes and pos. 5 sieve with small holes); 6 - vibrating drive;

7 - outlets; 8 - frame; 9 - control panel; 10 - rubber dampers; A, B, C, D - collector boxes

Adaptation and preparation of the equipment consisted in the removal of the lower sieves (pos. 4 and 5) and the replacement of the upper sieve, which was used in the experiments, with the chosen sizes of the holes, respectively $6.3 \mathrm{~mm}$ for nettle and $8.00 \mathrm{~mm}$ for chicory. A box of metal sheets was made on the entire length of the sieve, divided into 7 equal compartments, each with a length of $0.195 \mathrm{~m}$, as shown in Figure 2. The working parameters chosen for the appreciation of separation efficiency of chopped nettle and chicory fragments on the length of plane vibrating sieves were: feed rate $\left(25 \mathrm{~kg} \cdot \mathrm{h}^{-1} ; 40 \mathrm{~kg} \cdot \mathrm{h}^{-1}, 55 \mathrm{~kg} \cdot \mathrm{h}^{-1}\right)$ and sieve angle of inclination $\left(12.08^{\circ}, 13.33^{\circ}, 14.70^{\circ}\right)$.
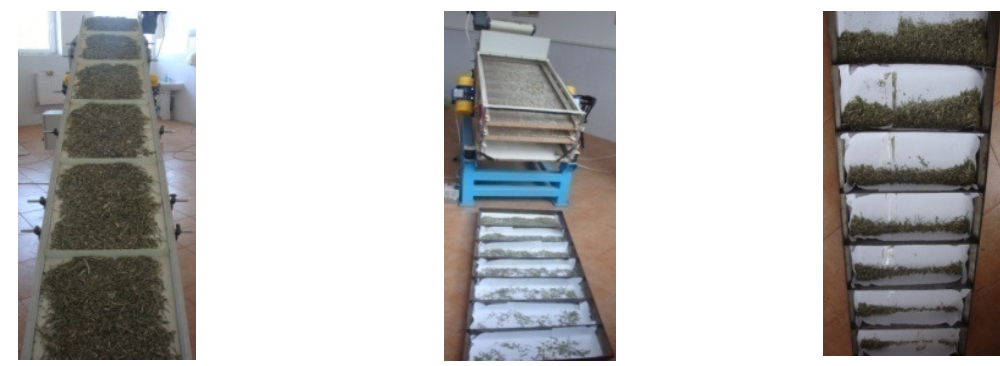

Fig. 2. Aspects during the experimental research [12]

The mass of feed rate of the sorter was adjusted by the speed of the conveyor belt. For each experiment, the plant fragments separated through the screen holes were collected in the box mounted below the sieve $\mathrm{C}$ with large holes. The amounts of chicory fragments collected in each compartment, noted by $1-7$, starting from feeding, were weighed with a Kern balance, with accuracy of $0.01 \mathrm{~g}$, and the obtained values were rated in a table to be easily recognized for processing and interpretation. The 
duration of the experiment was 30 seconds and the frequency of vibrations regulated by the frequency converter $50 \mathrm{~Hz}$ [12].

Interpretation of the results was done for the collection box with seven compartments, by the representation of functions of several variables, the case in which the dependent variable (total percentage amount of nettle or chicory fragments collected in the box) is simultaneously a function of several independent variables, $\mathrm{x}_{1}=\alpha$ respectively $\mathrm{x}_{2}=\mathrm{Q}$, replaced for each opening of screen holes and resulting in polynomial functions of $2^{\text {nd }}$ degree with two variables, having the general form shown in equation (1), [13]:

$$
f\left(x_{1}, x_{2}\right)=a_{0}+a_{1} \cdot x_{1}+a_{2} \cdot x_{2}+a_{3} \cdot x_{1}^{2}+a_{4} \cdot x_{1}+a_{5} \cdot x_{2}^{2} .
$$

For processing the experimental data the structure of a split testing experimental program was used, for 9 experiments, in Mathcad, given by the values of the independent variables and the values of the dependent variables from each experiment.

\section{Results and discussion}

Experimental data obtained by vegetable material separation on sieve length, have been distributed in percentage shares and graphically represented in Figures 3 and 4 . The performances of the separation equipment can be evaluated by studying the separation efficiency along the sieve, which is estimated by:

The intensity of separation along the sieve, which is defined by the ratio of the amount of fragments separated in each compartment of the box and the total amount of fragments subjected to the separation process. The intensity variation along the sieve depending on sieve angle of inclination, its feed rate and the size of sieve holes is of interest.
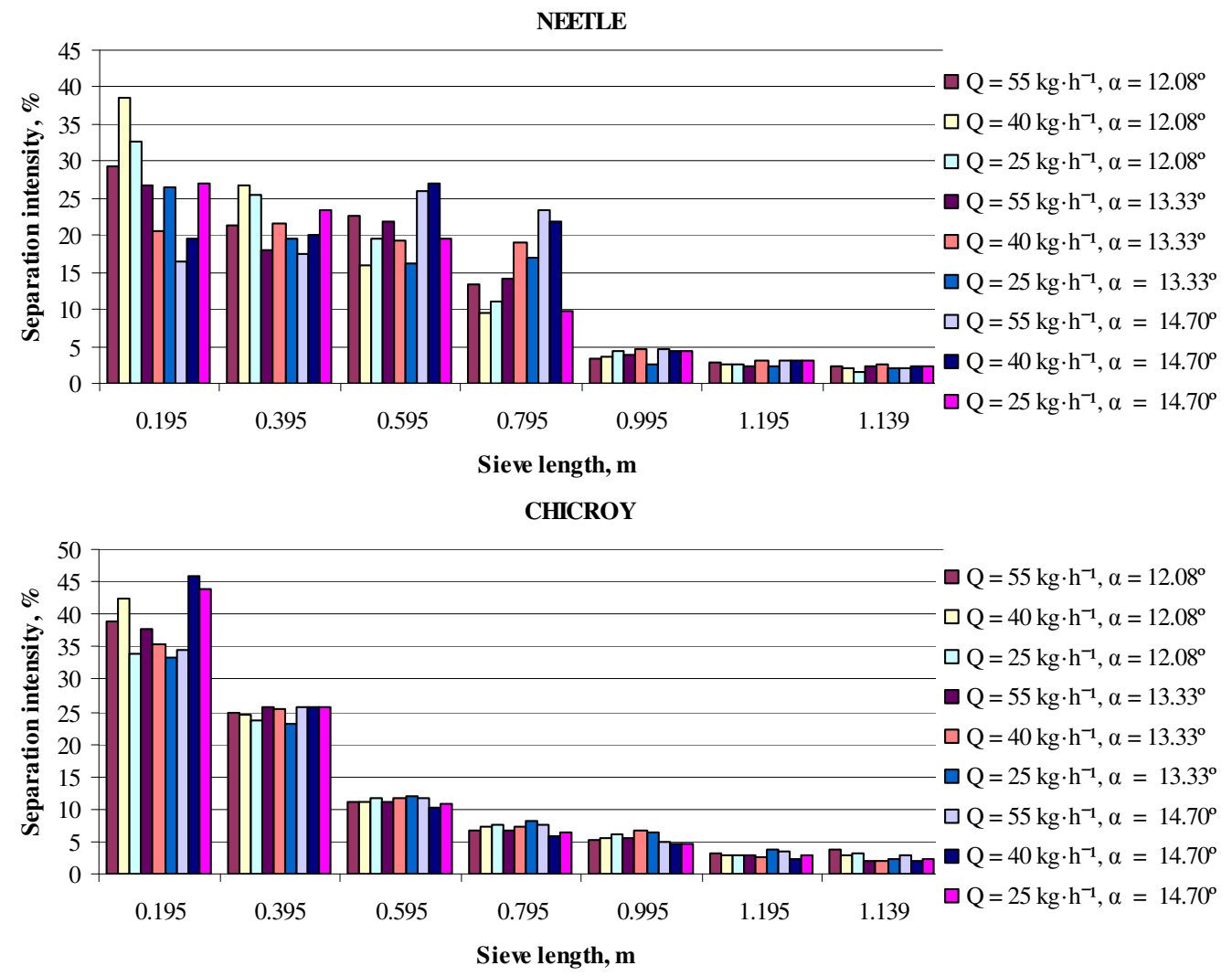

Fig. 3. Intensity variation of nettle and chicory fragment separation, on sieve length

Figure 3 shows the curves of the separation intensity length of the sieve according to three feed rates and the three angles of inclination; it is noted that the separation intensity is maximum in the feeding zone and decreases on the screen length for both studied plant species, being more and more insignificant towards the end of the grid. 
At nettle fragments the separation intensity is maximum in the middle of the sieve, between 0.595-0.795 $\mathrm{m}$ for the sieve large angle of inclination of 14.7 degrees while for small angles the separation degree is high in the first part of the grid, at approx. $0.195 \mathrm{~m}$ and becomes constant in the middle of the sieve and insignificant in its last part, no matter vegetable material feed rate.

In case of chicory fragments the separation intensity is maximum in the feeding zone at approx. $0.195 \mathrm{~m}$ on the length of the sieve, for all feed rates and all angles of inclination of the sieve. Also, a decrease is noticed in the separation intensity of chicory fragments when lowering the feed rate but also when decreasing the inclination angle of the sieve.

The cumulative separation along the sieve, defined as the percentage of the amount of fragments separated in the sieve compartments of $0.195 \mathrm{~m}$ from the initial amount of fragments undergoing the separation.
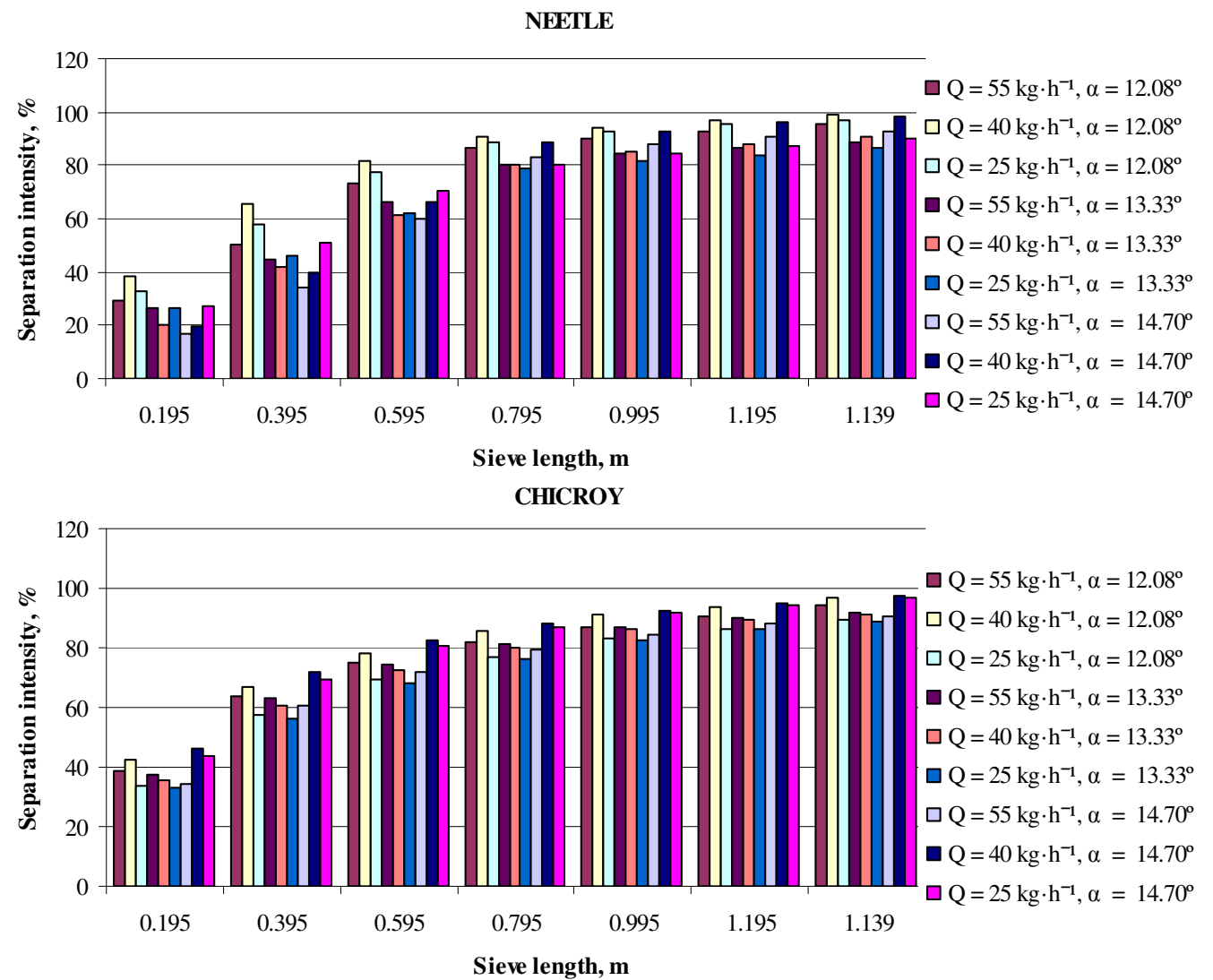

Fig. 4. Cumulative variation of nettle and chicory fragment separation, on sieves length

In Figure 4 it is noticed that cumulative separation increases with the sieve length and is different both for different feed rates and different angles of inclination of the sieve reported to the horizontal. Efficiency separation of plant fragments $\left(S_{f}\right)$ is expressed as a percentage $(\%)$ and is defined as the ratio between the amount of fragments separated into the 7 compartments of the collection box and the total amount of fragments that feed the sieve with different hole sizes.

Using the percentage experimental data from the cumulative separation of nettle and chicory fragments, the separation efficiency was interpreted by a polynomial function of the $2^{\text {nd }}$ degree, depending on the sieve angle of inclination $\left(x_{1}=\alpha\right)$ and the feed rate $\left(x_{2}=Q\right)$.

For nettle fragments the separation efficiency is graphically represented in Figure 5 and in relation 2 the function coefficients and the correlation coefficient $R=0.972$ are presented.

$$
f_{(\alpha, Q)}=834.134-112.059 \cdot \alpha+0.744 \cdot Q+4.044 \cdot \alpha^{2}+0.062 \cdot \alpha \cdot Q-0.019 \cdot Q^{2}
$$

For chicory fragments the separation efficiency is graphically represented in Figure 6 and in relation 3 the function coefficients and the correlation coefficient $R=0.937$ are presented.

$$
f_{(\alpha, Q)}=369.825-51.023 \cdot \alpha+3.016 \cdot Q+2.136 \cdot \alpha^{2}-0.14 \cdot \alpha \cdot Q-0.014 \cdot Q^{2}
$$



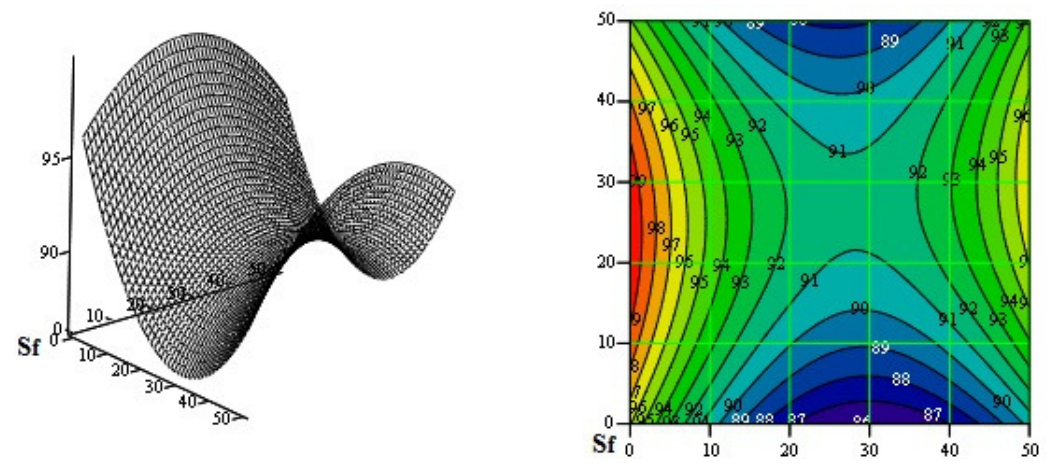

Fig. 5. Separation efficiency depending on the sieve angle of inclination and on the feed rate of nettle fragments
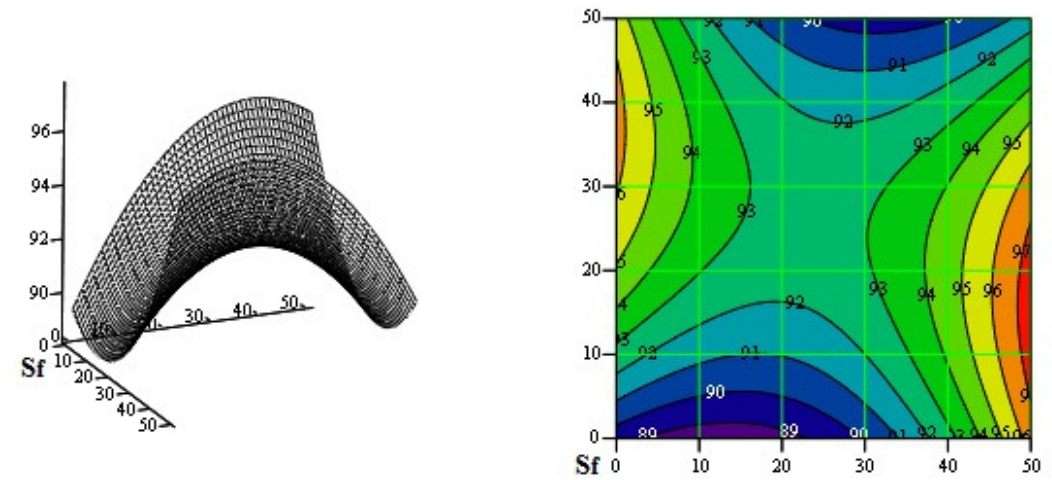

Fig. 6. Separation efficiency depending on the sieve angle of inclination and on the feed rate of chicory fragments

In Fig. 7 by comparison the experimental and the calculated values of separation efficiency, for each experiment, are presented depending on the studied parameters. Values of differences between the experimental and the calculated values obtained for the appreciation of the separation efficiency, depending on the sieve angle of inclination and the experimental feed rate, indicate very small differences of $0.12 \%$ for the small sieve inclination angle of 12.08 degree and high feed rate of $55 \mathrm{~kg} \cdot \mathrm{h}^{-1}$ at nettle fragments, respectively $0.13 \%$ for the high sieve inclination angle of 14.7 degree and small feed rate of $25 \mathrm{~kg} \cdot \mathrm{h}^{-1}$ at chicory fragments.
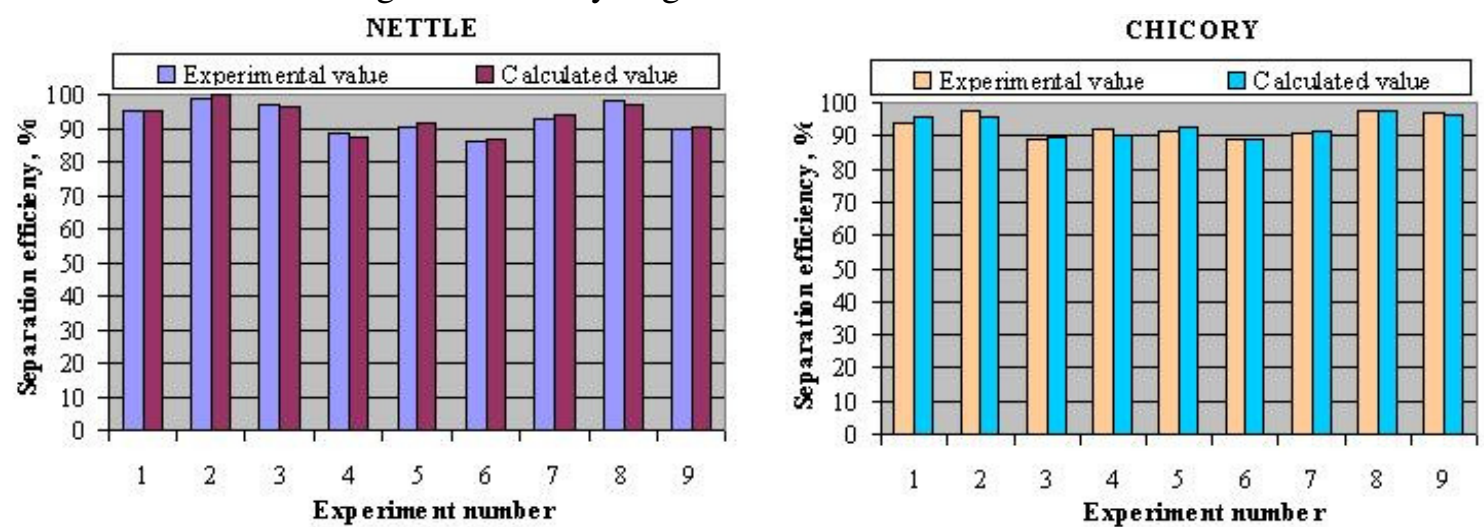

Fig. 7. Separation efficiency for nettle and chicory fragments for the experimental and theoretical values depending on the sieve angle of inclination and the feed rate

It can be seen that the applied polynomial equation correlates reasonably well with the values of the experimental data, for both sieves being obtained large correlation coefficients $R^{2}=0.972$, respectively $R^{2}=0.937$. 


\section{Conclusions}

1. Assuring the maximum separation efficiency of the chopped medicinal plants is possible by using sorting equipment having vibrating or oscillating plane sieves, with superior parameters for the working process.

2. Taking into account the morphological and biological characteristics of the medicinal plants (presence or absence of hairs, bioactive substance composition, etc.), the mechanical-structural characteristics of the plant fragments (slope angle, friction coefficient, size fragments, etc.) the requirements of pharmacopoeia (humidity, vegetative body used for the processing of medicinal plants) the separation process must be done within certain limits to keep the quality of the finished product.

3. Having in view: the type of the studied plant, nettle, the herbaceous plant, with leafy aspect and urticant hairs and chicory, the perennial plant with woody and hard stem, the research results were for different working parameters; after analysing the obtained correlation coefficients it can be noticed that optimal values for nettle fragment separation are at small inclination angles (12.08 degrees) and high feed rates $\left(55 \mathrm{~kg} \cdot \mathrm{h}^{-1}\right)$ while for chicory fragments separation the optimal values are at high inclination angles (14.7 degrees ) and small feed rates $\left(25 \mathrm{~kg} \cdot \mathrm{h}^{-1}\right)$.

\section{Acknowledgement}

This paper was financed by support of National Agency for Scientific Research and Innovation, NUCLEU Programme, no. 8N/09.03.2016, Ad. Act nr.1/2016, Project PN 16240303 - "Innovative technology and equipment for increasing the quality of plant raw material obtained from medicinal and aromatic plants, in the view of elaborating competitive organic products".

\section{References}

1. Ioancea L., Kathrein I. Conditioning and superior capitalization of vegetable raw material for food, Ceres Publishing, Bucharest, 1988, pp. 9.

2. Muscalu A., Vlăduţ V., Pruteanu A., Niţu M. Harvesting and primary processing of medicinal and aromatic plants, Terra Nostra Pub., Iaşi, România, 2012, pp. 25-26.

3. Allen T. Powder Sampling and Particle Size Determination, Particle size analysis by sieving, Ch. 4, Elsevier, Amsterdam, Netherlands, 2003, pp. 208-235.

4. Oztekin S., Martinov M. Medicinal and aromatic crops: harvesting, drying and processing, Editura Haworth Press, United States and Canada, 2007, pp.179-182.

5. Bontaş O., Nedeff V., Moşneguţu E. F., Panainte M., Tîrtoaca Irimia O. Behavior of solid particles on a flat oscillating surface, Environmental Engineering and Management Journal, vol. 12, no. 1, 2013, pp. 17-22.

6. Ene Gh., Sima T. Aspects regarding sifting materials on vibrating sieves I; II; Journal of Synthesis of Theoretical and Applied Mechanics, vol.4, no.1, pp. 15-25 and no.2, pp. 99-112, 2013.

7. Florea. C. Contributions to the improvement of technology and equipment used for the conditioning of herbs and berries before processing, Doctoral Thesis, Transylvania University Braşov, 2013, pp. 245.

8. Wang G., Tong X. Screening efficiency and screen length of a linear vibrating screen using DEM 3D simulation, Mining Science and Technology, vol. 21, 2011, pp. 451-455.

9. Ardelean A., Mohan Gh. Romanian Medicinal Flora, All Pub., Bucharest, pp.84, 324, 2008.

10. ***European Pharmacopoeia, 8th edition,EDQM Council of Europe Publishing, Strassbourg, 2011

11. ***Romanian Pharmacopoeia, 10th edition, Medical Publishing, 1993.

12. Pruteanu A., Vlăduţ V., Matache M., Muscalu A., Ungureanu N. Characterization of chicory herb (Cichorium intybus) of separation process on length of flat vibrating sieves, Proceedings of the 45-th International Symposium “ Actual Tasks on Agricultural Engineering”, Opatija, Croaţia, 2017, pp. 339-350.

13. Păunescu I., David L. Experimental research bases of biotechnical systems, Printech Publishing, Bucharest, 1999, pp. 37-42. 